\title{
Effect of Heat Treatment on Corrosion Behaviors of Mg-5Y- 2Nd-3Sm-0.5Zr Alloys
}

\author{
Yunwei Gui ${ }^{1}$, Quanan Li ${ }^{1,2, *}$, Jun Chen ${ }^{1,2}$ \\ ${ }^{1}$ School of Materials Science and Engineering, Henan University of Science and Technology, Luoyang \\ 471023, China \\ ${ }^{2}$ Collaborative Innovation Center of Nonferrous Metals, Luoyang 471023, China \\ *E-mail: liquanan2016@163.com
}

doi: $10.20964 / 2019.02 .25$

Received: 11 September 2018 / Accepted: 9 November 2018 / Published: 5 January 2019

\begin{abstract}
The effect of heat treatment on corrosion behaviors of Mg-5Y-2Nd-3Sm-0.5Zr alloy was investigated. The microstructure and precipitates were studied by X-ray diffraction spectroscopy (XRD), scanning electron microscope (SEM) and energy dispersive spectrometer (EDS). The weight loss rate of samples under different conditions was as-cast $>$ T6-6 h $>$ T6-18 h $>$ T4 $>$ T6-12 h. Open circuit potential (OCP) showed that T6-12 h samples have higher positive potentials than other samples. The potential polarization curves showed that the as-cast sample had the highest corrosion current density, while the T6-12 h sample had the lowest one. EIS results showed that heat treatment improved the corrosion resistance of $\mathrm{Mg}-5 \mathrm{Y}-2 \mathrm{Nd}-3 \mathrm{Sm}-0.5 \mathrm{Zr}$ alloy. It was owing to that the heat treatment process reduced the segregation phases in the Mg-5Y-2Nd-3Sm- $0.5 \mathrm{Zr}$ alloy and improved the uniformity of the alloy structure. The corrosion rate of different samples depended mainly on the second phases, which played a dual role, depending on their quantity and distribution. The presence of the second phases in the alloy will reduce the corrosion resistance, because it can be used as an effective cathode current. On the contrary, the homogeneous and fine second phases can play a good role in preventing the formation and expansion of corrosion.
\end{abstract}

Keywords: Mg-Y-Nd-Sm alloy; Heat treatment; Precipitated phases; Corrosion resistance; Electrochemistry

\section{FULL TEXT}

(C) 2019 The Authors. Published by ESG (www.electrochemsci.org). This article is an open access article distributed under the terms and conditions of the Creative Commons Attribution license (http://creativecommons.org/licenses/by/4.0/). 